\title{
RECONSTRUCTING POPULATION DYNAMICS OF YELLOW-CEDAR IN DECLINING STANDS: BASELINE INFORMATION FROM TREE RINGS
}

\author{
AMANDA B. STAN ${ }^{1 *}$, THOMAS B. MAERTENS ${ }^{1}$, LORI D. DANIELS ${ }^{1}$, and STEFAN ZEGLEN ${ }^{2}$ \\ ${ }^{1}$ Department of Geography, University of British Columbia, Vancouver, British Columbia V6T 1Z2, Canada \\ ${ }^{2}$ British Columbia Ministry of Forests and Range, Nanaimo, British Columbia V9T 6E9, Canada
}

\begin{abstract}
Yellow-cedar (Chamaecyparis nootkatensis (D. Don) Spach) forests of coastal British Columbia are apparently experiencing decline in a manner similar to that observed in southeastern Alaska. In this pilot study, we collect tree-ring data from live and standing dead yellow-cedar trees from four declining sites on the North Coast of British Columbia. We use this data to compare growth patterns at our sites to those of yellow-cedar trees at non-declining and declining sites in southwestern British Columbia and southeastern Alaska and, in addition, to assess the possibility of reconstructing yellow-cedar population dynamics in declining stands using dendrochronology. We found coherent growth patterns (i.e. marker years and periods of suppression) among yellow-cedar chronologies from non-declining and declining sites across a broad geographic range as well as unique growth patterns between our chronologies from declining sites and those from declining sites in nearby Alaska. Using outer-ring dates of increment cores, we were able to estimate time since death of decade- to century-old standing dead yellow-cedar trees, although the precision of the estimates was influenced by partial cambial mortality and erosion of outer rings. Our results provide baseline dendrochronological information that will be useful for planning future studies that assess growth-climate relations and reconstruct the long-term population dynamics of yellow-cedar in declining stands.
\end{abstract}

Keywords: Dendrochronology, forest decline, tree mortality, decay class, partial cambial mortality, Chamaecyparis nootkatensis, coastal British Columbia.

\section{INTRODUCTION}

In British Columbia, elevated mortality of yellow-cedar (Chamaecyparis nootkatensis (D. Don) Spach) occurs on more than 47,000 ha of coastal forests (Westfall and Ebata 2009). Landscape-, stand-, and tree-level patterns of mortality in British Columbia appear similar to those documented in southeastern Alaska (Hennon et al. 2005), where widespread mortality of yellowcedar, referred to as yellow-cedar decline, occurs on more than 200,000 ha of coastal forests (Lamb and Wurtz 2009). Throughout southeastern Alaska, dying and dead yellow-cedar trees occur at lower elevations ( $<300 \mathrm{~m}$ a.s.1.) in more northerly latitudes and slightly higher elevations in more southerly latitudes and are most common on south-facing slopes (Lamb and Wurtz 2009). Stands often show a radiating pattern of tree

\footnotetext{
*Corresponding author: astan@geog.ubc.ca
}

mortality, starting from a nucleus of trees that died decades ago in open bogs and scrubs and continuing in trees that died more recently in adjacent closed-canopy forests (D'Amore and Hennon 2006). Trees exhibit dieback symptoms that progress from initial root injury, to subsequent crown death as a unit, to eventual tree death (Hennon and Shaw 1997). Past research in Alaska suggested that biotic agents were not the primary cause of death of yellow-cedar (Hennon et al. 1990a, 1990b). More recent hypotheses implicate factors related to climate change. In particular, increasing late-winter temperatures are leading to reduced snowpack and early dehardening of yellow-cedar, leaving this species susceptible to late-winter freeze events (Hennon and Shaw 1994; Hennon et al. 2008; D'Amore et al. 2009). Similar climate-induced increases in tree mortality have been postulated as being associated with the dieback of forests worldwide (Allen et al. 2010). 
Given the climate change hypothesis and immense ecological, cultural, and economic value of yellow-cedar, understanding the population dynamics associated with the decline of this species is of paramount importance. To our knowledge, the only study on the population dynamics of yellow-cedar in declining stands is that of Hennon et al. (1990a), who assessed temporal changes in populations of standing dead trees. In that study, the authors applied a decayclass system for standing dead yellow-cedar (i.e. Hennon et al. 1990c) in which time-since-death estimates of trees in different decay classes were determined indirectly using dates of radial-growth releases of nearby living hemlock trees.

A dendrochronological approach that includes directly assessing dead as well as live trees offers potential to further assess the population dynamics of yellow-cedar and the decline phenomenon, as it can provide a means to reconstruct long-term trends in age structure, growth patterns, as well as recruitment and mortality rates. Because of yellow-cedar's great longevity ( $>1,000$ years) and high resistance to decay following death (Barton 1976), it may be possible to reconstruct the dynamics of this species far back in time using dendrochronology. Parish and Antos (2004, 2006) used dendrochronological techniques to successfully reconstruct the population dynamics of two, non-declining old-growth stands in southwestern British Columbia of which yellow-cedar was a canopy dominant. Although standing dead yellow-cedar trees were included in those studies, they constituted only a small proportion of each stand. In declining stands in Alaska and British Columbia, standing dead yellow-cedar trees occur in higher numbers (Hennon et al. 1990a; Hennon et al. 2005; D'Amore and Hennon 2006; Westfall and Ebata 2009). Estimating death dates of individual yellow-cedar trees may facilitate reconstructing long-term population dynamics in these stands. However, limited information exists on the ability to estimate time since death of yellow-cedar trees using dendrochronological techniques.

Dendrochronology may also be useful for evaluating additional aspects of yellow-cedar mortality and population dynamics in declining stands. For example, trees in declining stands may experience partial death of their cambiums at different points in time (e.g. Amoroso and Daniels 2010). By removing multiple increment cores from individual yellow-cedar trees, it is possible to assess the presence of partial cambial mortality and to quantify the error in estimating death dates using a single core per tree. This information will be valuable for developing practical sampling procedures for evaluating mortality rates in declining stands.

In this paper, we present a pilot study that explores the potential of dendrochronological techniques to reconstruct yellow-cedar population dynamics and decline. We use tree-ring data from live and standing dead yellow-cedar trees from four declining sites on the North Coast of British Columbia to address three objectives: (1) to crossdate ring-width series from live, asymptomatic trees for the purpose of (i) constructing sitespecific ring-width chronologies for assessing growth patterns and (ii) crossdating ring-width series from standing dead trees for estimating time since death, (2) to evaluate time since death of standing dead trees relative to their decay classes, and (3) to investigate the presence of partial cambial mortality in yellow-cedar. We compare our findings on crossdating quality, growth patterns, time since death, and partial cambial mortality of yellow-cedar to those of other studies in British Columbia and Alaska. Following our analyses, we compile baseline information on yellow-cedar's growth patterns at our sites relative to its growth patterns at sites across a broad geographic range and assess some of the benefits and limitations of using tree rings to reconstruct the population dynamics of this species. Together, this information will help inform and direct future studies that aim to better understand causes and effects of yellow-cedar decline.

\section{STUDY SITES}

We conducted this research at four sites within the North Coast Forest District of British Columbia (Figure 1), each of which were located in 2004 during an aerial survey near the city of Prince Rupert (Hennon et al. 2005). All sites consist of concentrated patches of dying and dead 


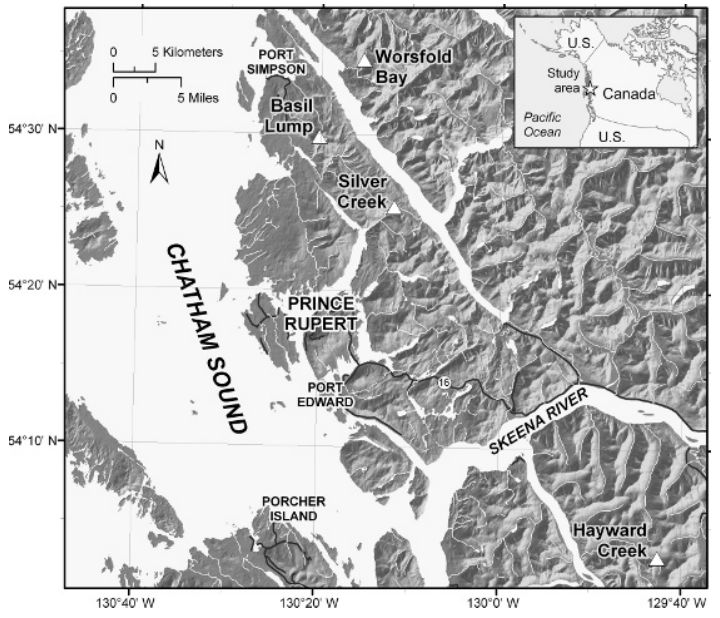

Figure 1. Location of the four study sites $(\triangle)$ with dying and dead yellow-cedar trees near Prince Rupert, British Columbia.

yellow-cedar trees, similar to the patches that are associated with the yellow-cedar decline phenomenon in southeastern Alaska. At the Worsfold Bay and Silver Creek sites, dying and dead trees are concentrated around the edges of bogs on gently sloping terrain. At the Basil Lump site, dying and dead trees are concentrated on a steeper slope, with adjacent bogs at level upslope and downslope positions. Dying and dead trees at the Hayward Creek site line the watercourse on gently sloping terrain.

At the time of sampling in 2007, total basal area of all live and standing dead trees $(>10 \mathrm{~cm}$ diameter at breast height (dbh)) at the four sites ranged from 30.69 to $67.62 \mathrm{~m}^{2} /$ ha (British Columbia Ministry of Forests and Range, unpublished data; Table 1). At the Worsfold Bay, Silver Creek, and Hayward Creek sites, yellow-cedar was the most dominant species (based on basal area of live and standing dead trees combined), whereas at the Basil Lump site, western hemlock (Tsuga heterophylla (Raf.) Sarg.) was the most dominant species. Four additional species occurred at one or more sites: mountain hemlock (Tsuga mertensiana (Bong.) Carr.), Pacific silver fir (Abies amabilis Dougl. ex J. Forbes), Sitka spruce (Picea sitchensis (Bong.) Carr.), and western redcedar (Thuja plicata Donn ex D. Don). Standing dead trees constituted 6 to $37 \%$ of the total basal area at each of the four sites (Table 1). At three of the four sites, yellow-cedar had the highest percentage of its basal area dead compared to all other species; 23,53 , and $38 \%$ of the basal area of yellow-cedar was dead at the Basil Lump, Silver Creek, and Hayward Creek sites, respectively (Table 1). At the Worsfold Bay site, 32\% of the basal area of yellow-cedar was dead, whereas $47 \%$ of the basal area of western hemlock was dead (Table 1).

Total density of all live and standing dead trees at the four sites in 2007 ranged from 567 to 1,023 stems/ha (Table 1). At the Silver Creek and Hayward Creek sites, yellow-cedar was the most abundant species (based on density of live and standing dead trees combined), whereas at the Worsfold Bay and Basil Lump sites, western hemlock was the most abundant species. At the four sites, total density of all live and standing dead saplings $(1-10 \mathrm{~cm} \mathrm{dbh})$ ranged from 533 to 1,666 stems/ha (Table 1). Most of the saplings were alive at each of the four sites (Table 1).

Using the Biogeoclimatic Ecosystem Classification system of British Columbia, all sites are located in the Coastal Western Hemlock (CWH) zone (Meidinger and Pojar 1991). The Worsfold Bay, Basil Lump, and Silver Creek sites are in the Central variant of the Very Wet Hypermaritime subzone (CWHvh2). At these sites, mean annual temperature is $5.6^{\circ} \mathrm{C}$, with a mean of $12.3^{\circ} \mathrm{C}$ in August and $0.2^{\circ} \mathrm{C}$ in January (very near the rainsnow temperature threshold), mean annual precipitation is 3,336 mm, and mean growing season (May to September) precipitation is $951 \mathrm{~mm}$ (Wang et al. 2006). The Hayward Creek site is in the Submontane variant of the Very Wet Maritime subzone (CWHvm1), which is more continental than the CWHvh2. Here, summers are warmer, winters are colder, and precipitation is higher than at the other three sites (Wang et al. 2006). Elevations are 366, 518, 305, and $366 \mathrm{~m}$ a.s.l. at the Worsfold Bay, Basil Lump, Silver Creek, and Hayward Creek sites, respectively.

\section{METHODS}

\section{Field Procedures}

From a random point at each site, we entered patches of dying and dead trees and systematically traversed them to locate and core at least 20 
Table 1. Basal area and density of live and standing dead saplings $(1-10 \mathrm{~cm} \mathrm{dbh})$ and trees $(>10 \mathrm{~cm} \mathrm{dbh})$ at four sites near Prince Rupert, British Columbia (British Columbia Ministry of Forests and Range, unpublished data). For basal area, the percentage dead of yellow-cedar, western hemlock, and additional species along with the percentage dead of the total are given. Values are means for three 0.01 ha circular plots (5.64 m radius) that were established within the patch of dying and dead trees at each site where we collected increment cores from live, asymptomatic and standing dead yellow-cedar trees.

\begin{tabular}{|c|c|c|c|c|c|c|c|c|}
\hline \multirow[b]{3}{*}{ Site $^{1}$} & \multirow[b]{3}{*}{ Species } & \multicolumn{3}{|c|}{ Basal Area $\left(\mathrm{m}^{2} / \mathrm{ha}\right)$} & \multicolumn{4}{|c|}{ Density (stems/ha) } \\
\hline & & \multicolumn{3}{|c|}{ Trees } & \multicolumn{2}{|c|}{ Saplings } & \multicolumn{2}{|c|}{ Trees } \\
\hline & & Live & Dead & $\%$ Dead & Live & Dead & Live & Dead \\
\hline \multirow[t]{4}{*}{ WB } & yellow-cedar & 15.40 & 7.34 & 32 & 167 & 0 & 167 & 100 \\
\hline & western hemlock & 4.23 & 3.72 & 47 & 700 & 33 & 200 & 100 \\
\hline & additional species & 0 & 0 & - & 33 & 0 & 0 & 0 \\
\hline & Total & 19.63 & 11.06 & 36 & 900 & 33 & 367 & 200 \\
\hline \multirow[t]{4}{*}{ BL } & yellow-cedar & 6.97 & 2.12 & 23 & 333 & 0 & 167 & 67 \\
\hline & western hemlock & 28.50 & 0 & - & 167 & 0 & 433 & 0 \\
\hline & additional species & 0 & 0 & - & 33 & 0 & 0 & 0 \\
\hline & Total & 35.47 & 2.12 & 6 & 533 & 0 & 600 & 67 \\
\hline \multirow[t]{4}{*}{$\mathrm{SC}$} & yellow-cedar & 13.01 & 14.38 & 53 & 433 & 100 & 333 & 400 \\
\hline & western hemlock & 4.41 & 1.93 & 30 & 933 & 67 & 100 & 67 \\
\hline & additional species & 10.10 & 0 & - & 133 & 0 & 133 & 0 \\
\hline & Total & 27.52 & 16.31 & 37 & 1,499 & 167 & 566 & 467 \\
\hline \multirow[t]{4}{*}{$\mathrm{HC}$} & yellow-cedar & 21.32 & 12.81 & 38 & 133 & 0 & 300 & 100 \\
\hline & western hemlock & 5.42 & 0.44 & 8 & 333 & 0 & 133 & 33 \\
\hline & additional species & 24.95 & 2.68 & 10 & 533 & 0 & 167 & 67 \\
\hline & Total & 51.69 & 15.93 & 24 & 999 & 0 & 600 & 200 \\
\hline
\end{tabular}

${ }^{1} \mathrm{WB}=$ Worsfold Bay, BL = Basil Lump, $\mathrm{SC}=$ Silver Creek, and $\mathrm{HC}=$ Hayward Creek. Note: Additional species include mountain hemlock (Tsuga mertensiana (Bong.) Carr.), Pacific silver fir (Abies amabilis Dougl. ex J. Forbes), Sitka spruce (Picea sitchensis (Bong.) Carr.), and western redcedar (Thuja plicata Donn ex D. Don).

yellow-cedar trees in each of two status classes: live, asymptomatic trees and standing dead trees. We visually assessed the crowns and boles of trees ( $\mathrm{dbh} \geq 10 \mathrm{~cm}$ ) to separate healthy from declining and dead. Asymptomatic trees were those that had live and "healthy" crowns (i.e. green) and no obvious bole damage. We sampled large, and presumably old, asymptomatic trees to construct long, robust site chronologies. Standing dead trees were assessed according to the six-class decay system for yellow-cedar described by Hennon et al. (1990c). Nearly all of the sampled trees were in the most recent decay classes I (at least $10 \%$ of the total foliage retained) to III (at least $10 \%$ of the total secondary branches retained and most twigs missing), as it was difficult to obtain sound increment cores with intact sapwood and outer rings from trees in more advanced stages of decay.

From each tree, we extracted two increment cores at a height of approximately $30 \mathrm{~cm}$ above the ground. In most instances, the second core was taken at a location $\geq 90^{\circ}$ from the first core. However, for standing dead trees, we took the second core through the face of scars located at the base of trees that likely formed prior to the death of other parts of the bole and did not appear to be the result of abrasion. By coring through these scars, we attempted to obtain data that maximized the difference in outer-ring dates between cores from the same tree to use in our analyses of partial cambial mortality. It is important to note that in using this sampling approach we did not intend to capture cambial mortality in yellow-cedar trees with explicit "stripbark morphologies". In live individuals with such growth forms, strips of dead cambium alternate with strips of live cambium along the length of the bole, and the parts of the crown that are associated with the dead cambium are dead as well. Instead, our sampling approach was aimed at capturing damage potentially associated with root death caused by freezing injury. 


\section{Laboratory Procedures}

We prepared all cores from each of the four sites following the procedures of Stokes and Smiley (1968). Ring-width series from live, asymptomatic trees were visually crossdated (Yamaguchi 1991), first within individual trees and then among all trees from a single site. We measured the ring widths of all series from asymptomatic trees to the nearest $0.001 \mathrm{~mm}$ using a stereozoom microscope and a Velmex sliding-stage micrometer interfaced with MeasureJ2X software. We used the program COFECHA (Holmes 1983; Grissino-Mayer 2001) to detect crossdating errors and to calculate average mean sensitivity and average interseries correlation values, which we used to describe the crossdating quality of the ring-width series from each site. Average mean sensitivity measures the strength of the year-to-year variability in all series, and average interseries correlation measures the strength of the signal common to all series. Ringwidth series that could not be confidently crossdated were removed from the data set.

We used the program ARSTAN (version 41d for Windows XP; Cook 1985) to detrend and standardize ring-width series from asymptomatic trees and to create a mean chronology for each site. Prior to detrending, we averaged the two ringwidth series per tree, using only those years that were accurately dated and common to both series. To detrend each series, we first fitted a negative exponential curve, line with a negative slope, or horizontal line, and subsequently fitted an 80-year cubic spline with a $50 \%$ frequency response. The first detrending was intended to remove trends associated with tree age and size, whereas the second was intended to remove trends associated with stand dynamics. After each detrending, each series was standardized to obtain a tree-ring index value for each year by dividing the actual ringwidth measurements by the values of the fitted curve, line, or spline. Finally, we created standard chronologies for the individual sites by averaging the index values of each series using a bi-weight robust mean (Cook et al. 1990).

Following the protocols for the asymptomatic trees, we measured the ring widths of all standing dead trees. We used COFECHA to statistically crossdate individual ring-width series from standing dead trees against the corresponding set of site-specific, dated ring-width series from asymptomatic trees, which allowed us to assign a calendar year to each tree ring and thus estimate the year a tree died. After statistical crossdating, we visually examined the ring-width series from each standing dead tree to ensure that all were accurately dated and had intact outer rings. Ringwidth series that could not be crossdated or that had broken or indiscernible outer rings were removed from the data set. For each standing dead tree remaining in the data set, we first estimated its year of death using the most recent outer-ring date of the two ring-width series per tree and then calculated its time since death (i.e. 2007 - year of death).

\section{Data Analyses}

We compared the crossdating quality of the ring-width series from asymptomatic trees among the four sites. In addition, we assessed growth patterns of asymptomatic trees both graphically, by comparing negative and positive marker rings (i.e. rings that differed from the mean tree-ring index by \pm 1 standard deviation or more) and suppressions (i.e. multi-year periods of below-average growth) among the site-specific chronologies, as well as quantitatively, by calculating Pearson's $(r)$ correlation coefficients between individual chronologies. For standing dead trees, we combined individuals from all sites and used ANOVA to test for differences in time since death among decay classes. To meet the assumptions of normality and homogeneity of variance of ANOVA, time-since-death estimates were transformed using a natural logarithm. We used Tukey's HSD test to contrast means among decay classes. To estimate the frequency and minimum duration of partial cambial mortality in yellow-cedar, we compared the outer-ring dates of the two ring-width series from the same standing dead tree. Finally, we assessed whether the difference in outer-ring dates between individual ringwidth series from the same standing dead tree showed an increasing trend with increasing time since death by calculating Spearman's $(\rho)$ correlation coefficient. Statistical analyses were done using $\mathrm{R}$, version 2.5.0 (R Development Core Team 2007). 
Table 2. Summary characteristics for the ring-width series of yellow-cedar from four sites near Prince Rupert, British Columbia.

\begin{tabular}{lcccc}
\hline Site $^{1}$ & No. Series & No. Trees & Inter. Corr. $^{2}$ & Mean Sens. \\
\hline WB & 32 & 17 & 0.47 & 0.24 \\
BL & 39 & 20 & 0.51 & 0.23 \\
SC & 36 & 19 & 0.46 & 0.23 \\
HC & 34 & 19 & 0.46 & 0.25 \\
\hline
\end{tabular}

${ }^{1} \mathrm{WB}=$ Worsfold Bay, BL $=$ Basil Lump, $\mathrm{SC}=$ Silver Creek, and $\mathrm{HC}=$ Hayward Creek.

${ }^{2}$ Average interseries correlation of all ring-width series.

${ }^{3}$ Average mean sensitivity of all ring-width series.

\section{RESULTS}

\section{Live, Asymptomatic Trees}

Crossdating quality of the ring-width series from live, asymptomatic trees was similar among the four sites (Table 2). Average mean sensitivity values were $0.24 \pm 0.01$ (mean $\pm \mathrm{SD}$ here and throughout the text). Average interseries correlation values were $0.48 \pm 0.02$.

Growth patterns of live, asymptomatic trees were similar among the four sites (Figure 2; Table 3). The site chronologies ranged from 410 to 488 years (Figure 2). Between 1798 and 2006, the period in which all four chronologies had a minimum of 10 trees, there was an average of $32.0 \pm 2.9$ negative and $25.0 \pm 1.7$ positive marker rings. During that same period, all four chronologies had negative marker rings in seven years: 1811, 1876, 1936, 1958, 1960, 1986, and 1987; three of the four chronologies had negative marker rings in an additional 16 years: 1810, 1812, 1835, 1856, 1873, 1875, 1877, 1887, 1894, 1896, 1917, 1918, 1920, 1926, 1972, and 1998 (Figure 2). Between 1798 and 2006, periods of suppressed growth lasting three to eight years occurred in all four chronologies in the late 1800 s through 1810 s, $1870 \mathrm{~s}$, the late $1910 \mathrm{~s}$ through the early $1920 \mathrm{~s}$, 1930s, 1950s, 1970s, and the late 1980s (Figure 2). In addition, correlation analysis indicated a strong common growth signal for the period 1798-2006. Correlations between individual site chronologies ranged from 0.52 to 0.78 ( $\mathrm{p}<0.001)$, with an average of $0.64 \pm 0.11$ (Table 3). Correlations between the Hayward Creek chronology and each of the other three chronologies were lowest (Table 3).

\section{Standing Dead Trees}

We successfully crossdated 121 of 158 (77\%) ring-width series from standing dead yellow-cedar and estimated the year of death of 70 of $79(89 \%)$ trees. Of the 37 remaining ring-width series, eight were too suppressed to confidently crossdate and 29 had broken or indiscernible outer rings. Except for two trees at the Worsfold Bay site, all trees had outer-ring dates between 1949 and 2006; therefore, for 68 of the 70 trees assessed, time since death in 2007 ranged from 1 to 58 years. The two exceptions were trees in more advanced stages of decay: one with an outer-ring date of 1903 (decay class IV) and the other with an outer-ring date of 1728 (decay class V).

Time since death increased significantly $(\mathrm{F}=$ $78.65, \mathrm{p}<0.001)$ with advanced stages of decay (Figure 3). Standing dead trees in decay classes I, II, and III died $4.71 \pm 1.87,12.56 \pm 5.31$, and $25.15 \pm 9.87$ years ago, respectively. Three trees in decay class IV (time since death $=40,58$, 104 years) and one tree in decay class V (time since death $=279$ years) were not included in the analysis because of small sample sizes for those classes.

The outer-ring dates of the two ring-width series from the same standing dead tree $(n=51)$ differed between 0 and 13 years (Figure 4 ). A total of $16 \%$ had the same outer-ring date. In contrast, $53 \%$ had dates that differed from 1 to 3 years, and $31 \%$ had dates that differed by more than 3 years. The difference in outer-ring dates between individual ring-width series from the same standing dead tree showed an increasing trend with increasing time since death (Spearman's $\rho=$ $0.56, \mathrm{p}<0.001$; Figure 4).

\section{DISCUSSION}

\section{Live, Asymptomatic Trees}

Crossdating quality of the ring-width series from live, asymptomatic trees, as expressed by average mean sensitivity and average interseries correlation values, is similar among the four sites. 


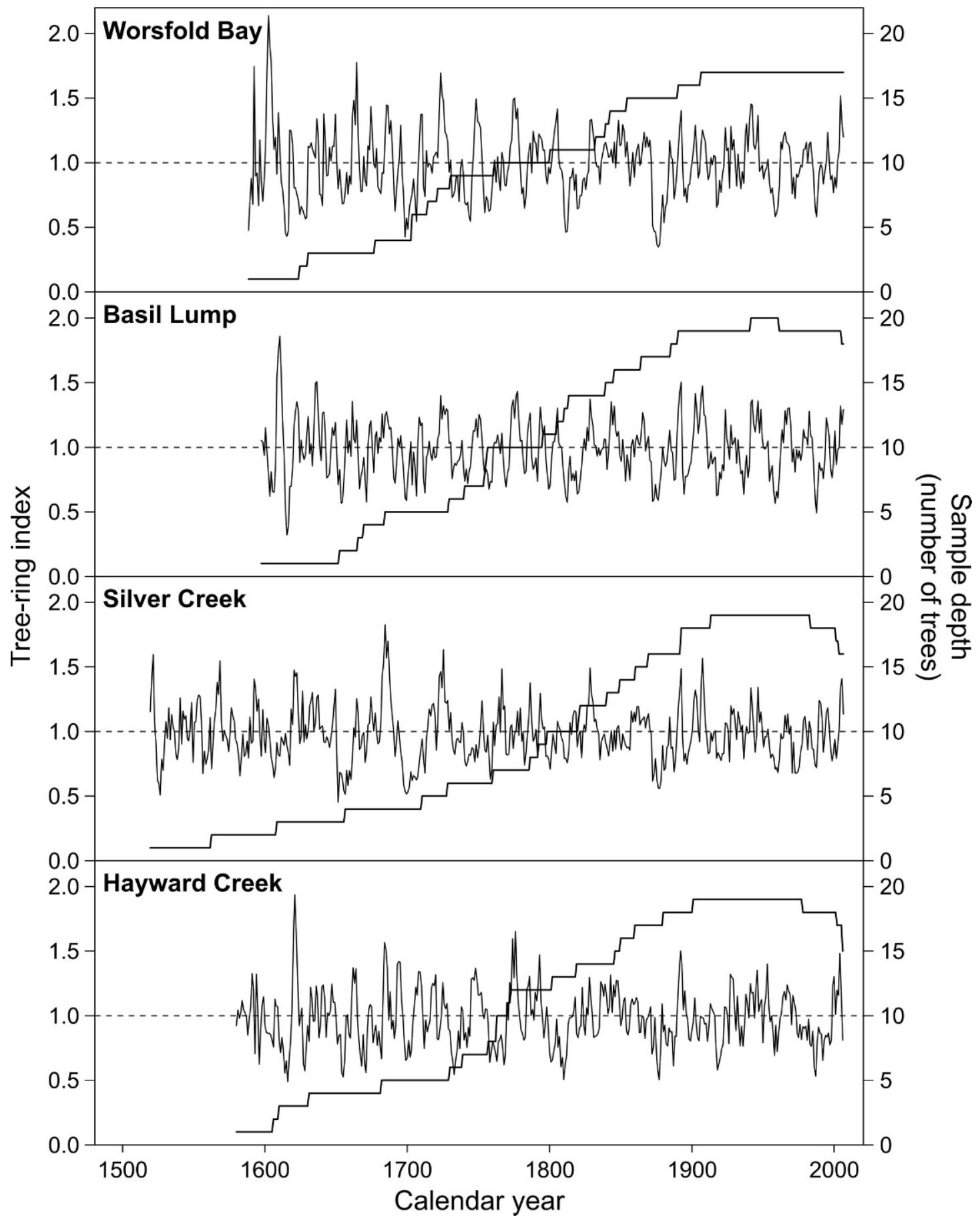

Figure 2. Standard ring-width chronologies of yellow-cedar from four sites near Prince Rupert, British Columbia. 
Table 3. Pearson's $(r)$ correlation coefficients for the period in which all yellow-cedar chronologies had a minimum of 10 trees: 1798-2006. All values are significant at $\mathrm{p}<0.001$.

\begin{tabular}{lcccc}
\hline Site $^{1}$ & WB & BL & SC & HC \\
\hline WB & 1.00 & 0.78 & 0.72 & 0.56 \\
BL & & 1.00 & 0.73 & 0.54 \\
SC & & 1.00 & 0.52 \\
HC & & & 1.00 \\
Grand mean & $=0.64 \pm 0.11(\mathrm{SD})$ & & \\
\hline
\end{tabular}

${ }^{1} \mathrm{WB}=$ Worsfold Bay, BL $=$ Basil Lump, $\mathrm{SC}=$ Silver Creek and $\mathrm{HC}=$ Hayward Creek.

In addition, these values for ring-width series from our four sites are comparable to those for all other known yellow-cedar ring-width series, which are from higher-elevation $(>1,000 \mathrm{~m}$ a.s.1.), nondeclining sites in southwestern British Columbia (Laroque and Smith 1999; Kellner et al. 2000; Parish 2005) and lower-elevation (<300 m a.s.1.), non-declining and declining sites in southeastern Alaska (Beier et al. 2008). Our average mean sensitivity values are in the middle of the range of all known values for yellow-cedar, indicating that trees at our sites are intermediate in their sensitivity to year-to-year environmental fluctuations. However, in all but one instance (i.e. Mount Washington, Laroque and Smith 1999), our average interseries correlation values exceed all other known values for yellow-cedar. Overall, these findings provide evidence of a moderately strong common signal and high-quality crossdating among the individual ring-width series at each of our sites.

Common marker rings and periods of suppressed growth among the chronologies indicate similar growth patterns of yellow-cedar at each of the four sites. Strong correlations between individual chronologies for the period 1798-2006 further indicate coherency in growth patterns. Of all the correlations, those between the Hayward Creek chronology and each of the other three chronologies are lowest. These patterns may reflect unique site characteristics or differing weather events at Hayward Creek, as this site is more distant from the others as well as more continental. Still, our findings suggest that growth of yellow-cedar at each of the four sites results from similar environmental controls.

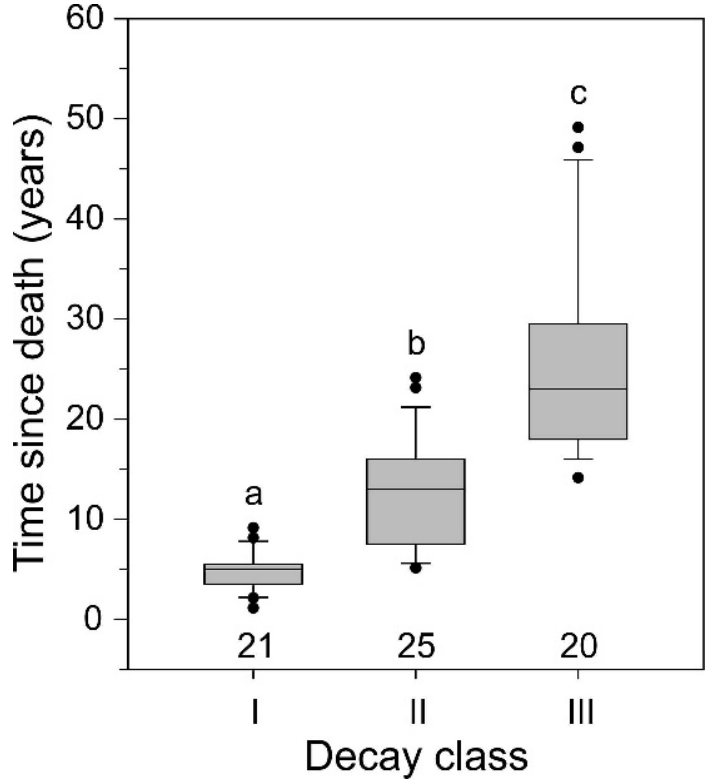

Figure 3. Box plots of time since death of standing dead yellowcedar trees $(n=66)$ in decay classes I to III at four sites near Prince Rupert, British Columbia. Different letters indicate significant differences among means at $p<0.001$. Values within the plot along the $\mathrm{x}$-axis are sample sizes. The horizontal line in each box is the median, the lower and upper limits of each box are the 25 th and 75 th percentiles, the lines are the 5 th and 95 th percentiles, and the circles are outliers.

Furthermore, spatially coherent growth patterns exist among yellow-cedar trees at our sites and those at sites in southeastern Alaska and southwestern British Columbia. Along a northsouth gradient, there is general synchrony of negative marker rings and suppressions among chronologies (Figure 5). Specifically, for the period 1798-2006, chronologies from sites in southeastern Alaska (Beier et al. 2008) are most similar to chronologies from our sites on the North Coast of British Columbia, whereas chronologies from sites in southwestern British Columbia (Laroque and Smith 1999; Parish 2005) are most similar to each other. Our chronologies share growth patterns in common with chronologies from southeastern Alaska and southwestern British Columbia and are from sites that lie in between those two locations (Figure 5). Although synchronous growth patterns exist along a north-south gradient, negative marker rings occur in 1812, 1876, and 1887 and suppressions occur in the 1870s, 


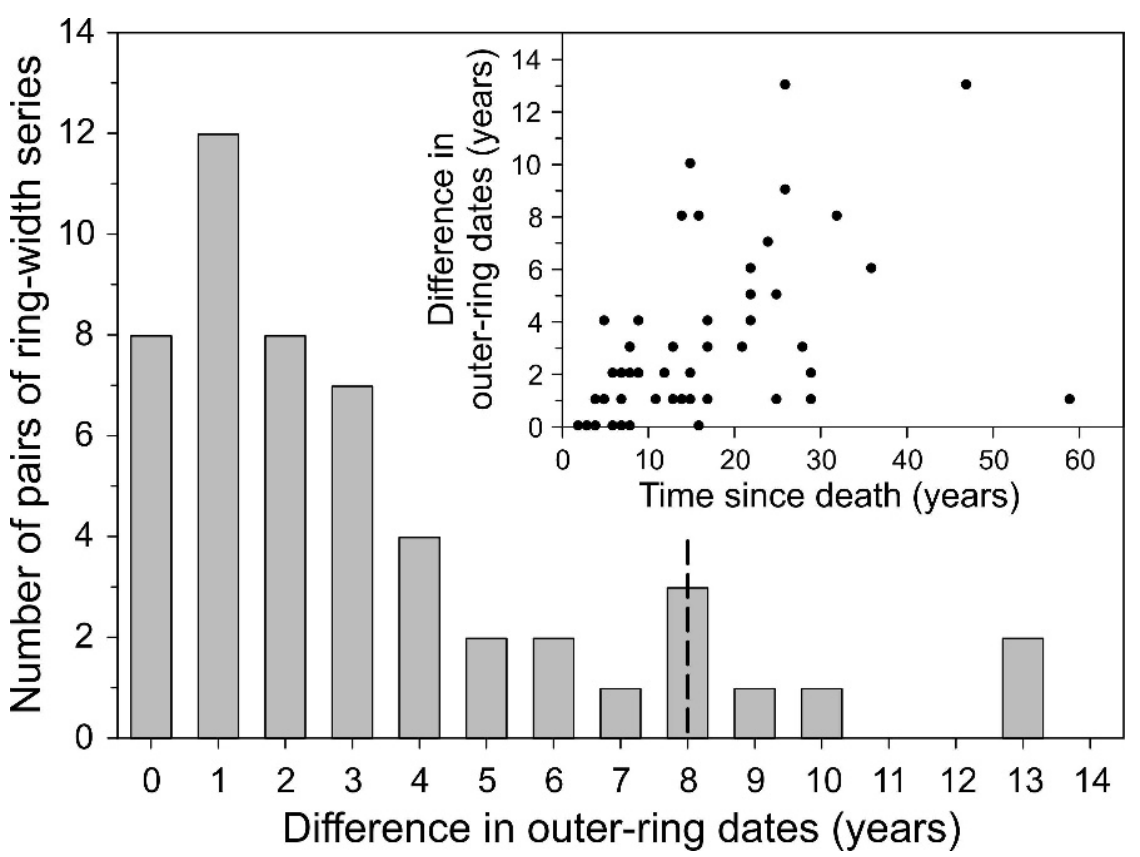

Figure 4. Frequency distribution of the difference in outer-ring dates between individual yellow-cedar ring-width series from the same standing dead tree $(\mathrm{n}=51)$. Vertical dashed line is the 90th percentile. Inset: Scatter plot of the difference in outer-ring dates between individual yellow-cedar ring-width series from the same standing dead tree by time since death (Spearman's $\rho=0.56$, $\mathrm{p}<0.001)$.

1890s, and 1950s in chronologies from sites in southeastern Alaska to southwestern British Columbia (Figure 5), demonstrating the coherence of growth patterns of yellow-cedar across a broad geographic range.

Interestingly, our chronologies from declining sites on the North Coast of British Columbia have negative marker rings in common with chronologies from declining sites in southeastern Alaska (i.e. 1926, 1936, 1986, 1987; Figure 5; Beier et al. 2008). For the sites in Alaska, Beier et al. (2008) found a link between growth of yellowcedar and late-winter (March-April) temperature and precipitation. In that same study, years of low growth often coincided with years of potential climatic stress to trees (Beier et al. 2008). For example, negative marker rings, low snowfall, and consecutive, prolonged, and intensive freeze events all occurred in 1986 and 1987. Based on the resemblance of the growth patterns of our yellowcedar trees to those of trees in Alaska, similar growth-climate relations are plausible at declining yellow-cedar sites in British Columbia. If this is the case, yellow-cedar in British Columbia may be vulnerable to damage from similar climatic stressors as seen in Alaska, which will have consequences for the long-term growth and population dynamics of this species.

\section{Standing Dead Trees}

Our results demonstrate that year of death can be estimated for decade- to century-old standing dead yellow-cedar trees using dendrochronology. Other studies have found similar estimates as ours for time since death of this species, with reported values of over 100 years (Hennon et al. 1990c; Parish and Antos 2004) and 200 years (Kellner et al. 2000) for standing dead trees. Successful crossdating of long-dead yellowcedar trees is not surprising, especially considering that this species occurs in cool climates and is known to be highly decay resistant (Barton 1976).

Our time-since-death estimates of yellowcedar trees in decay classes I to III are very similar to those of yellow-cedar trees in the same decay 


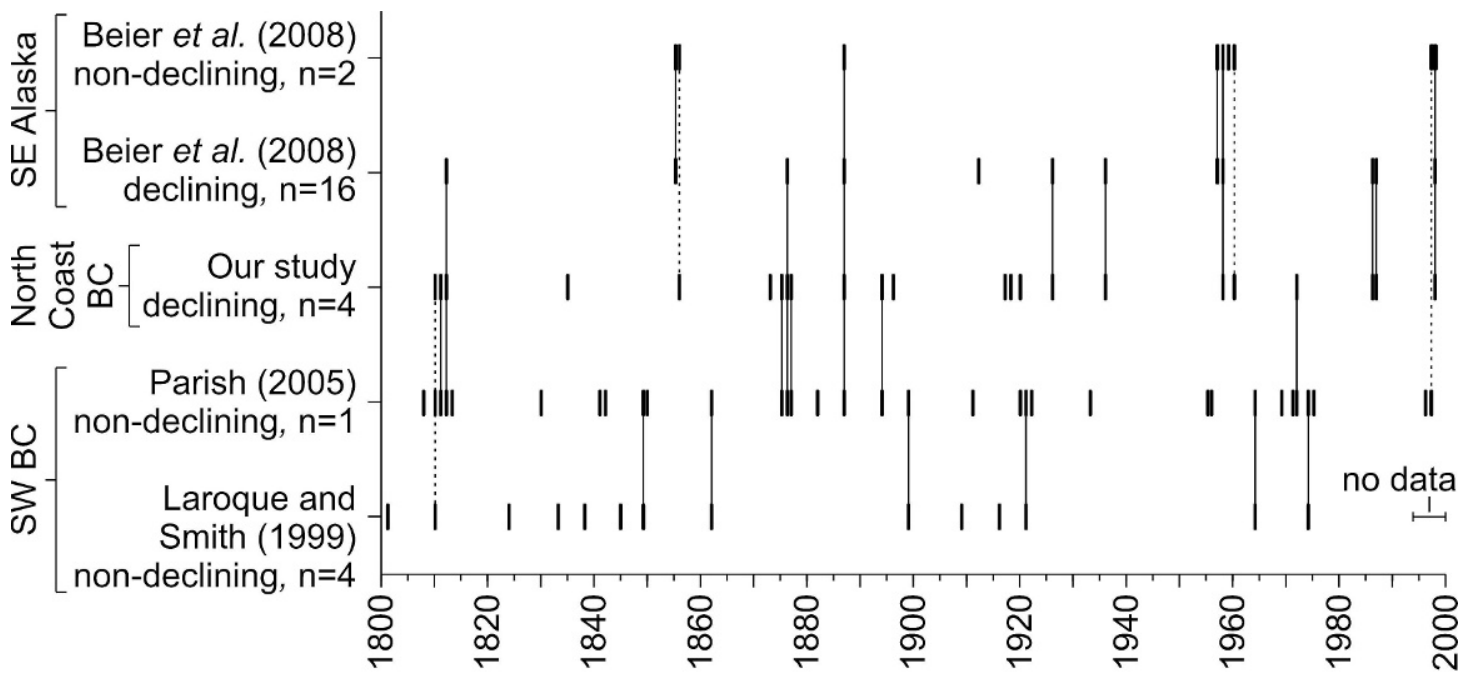

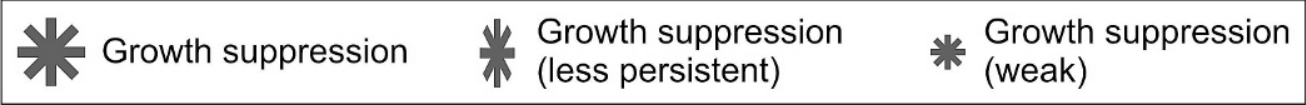

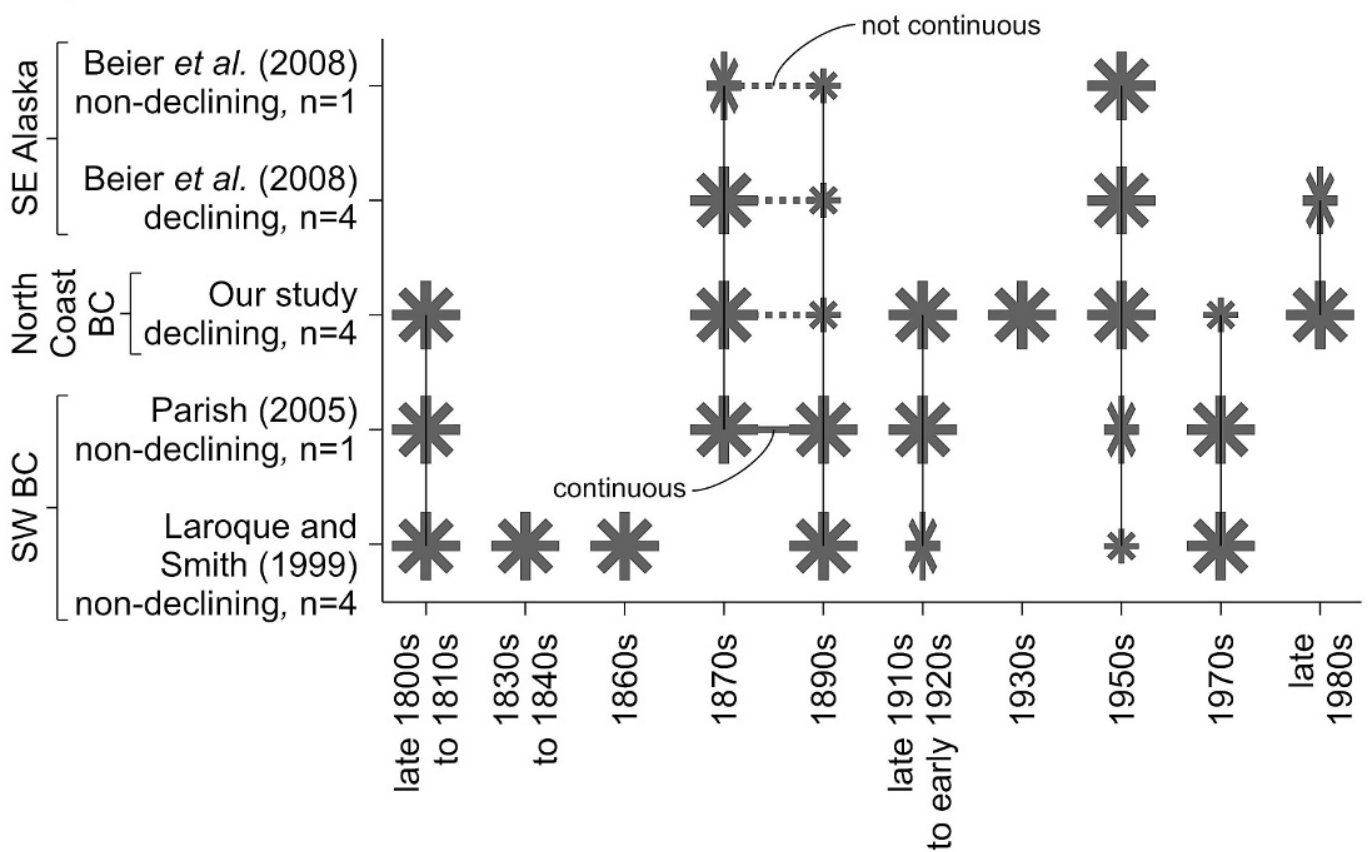

Figure 5. Top: Summary of negative marker rings (i.e. rings that differed from the mean tree-ring index by -1 standard deviation or more) in all known yellow-cedar ring-width chronologies from sites at three locations along a north-south gradient: southeastern Alaska ( $<300 \mathrm{~m}$ a.s.1.), North Coast of British Columbia (300-600 m a.s.1.), and southwestern British Columbia ( $>1,000 \mathrm{~m}$ a.s.1.). Marker rings for our chronologies and those of Beier et al. (2008) and Parish (2005) were obtained from COFECHA outputs, whereas marker rings for the chronologies of Laroque and Smith (1999) were taken from Table 2 of their manuscript. Marker rings present in $>50 \%$ of the chronologies from each study or decline category within a study are shown. However, because of the high number of chronologies from declining sites in Alaska, marker rings that are present in at least $50 \%$ of those chronologies are shown to improve interpretations of patterns across sites from all locations. Bottom: Summary of growth suppressions (i.e. multi-year periods of below-average growth estimated via visual assessments) in all known yellow-cedar ring-width chronologies. Growth suppressions present in $>50 \%$ of the chronologies from each study or decline category within a study are shown. 
classes in southeastern Alaska (Hennon et al. 1990c), although slightly lower in variability. Using dates of radial-growth releases of hemlocks growing beneath standing dead yellow-cedar trees, Hennon et al. (1990c) estimated time since death as $3.6 \pm 3.2,13.6 \pm 6.9$, and $26.2 \pm 12.3$ years for decay classes I, II, and III, respectively. Although slight, the lower variability in our estimates demonstrates the value of directly sampling standing dead trees whenever possible to attain more precise time-since-death estimates of individuals in different decay classes.

Still, as our results and those of Hennon et al. (1990c) illustrate, time-since-death estimates of yellow-cedar trees within a decay class are quite variable, regardless of the technique that is used to obtain them. High variability in time-since-death estimates has been the case for other species (e.g. Mast and Veblen 1994; Daniels et al. 1997). Therefore, the decision to infer time since death using decay class or dendrochronological dating will be, at least in some instances, a matter of the level of precision needed to address the goals of a study. Although direct dendrochronological dating can sometimes provide more precise estimates, this approach does have its shortcomings. Besides the fact that directly sampling standing dead trees may not be possible because of erosion of outer rings, even when it is possible, the correspondence of an outer-ring date to the actual death date of a tree is complicated by the potential for a tree to produce partial or no annual rings as it dies.

A difference in outer-ring dates between individual ring-width series from the same standing dead tree suggests that partial cambial mortality occurs in yellow-cedar at the study sites, implying an additional source of potential error when estimating time since death. In most instances, outer-ring dates differed by three years or less, but differences as high as 13 years occurred. These results suggest a gradual cessation of radial growth around the circumference of individual yellow-cedar trees, which tends to happen over just a few years, rather than decades. Collecting multiple increment cores per tree allows us to estimate a minimum duration of mortality of yellow-cedar in declining stands. This estimate represents the degree of error when determining year of death using only a single core from a standing dead tree. However, because this estimate increases with time since death, it may represent error from erosion of rings over time as well as error from partial cambial mortality.

Despite some shortcomings, dendrochronology can provide valuable information on time since death, decay rates, and partial cambial mortality of yellow-cedar, which will be useful for reconstructing various aspects of its population dynamics in declining stands. For example, estimating time since death of individual trees will facilitate reconstructing the frequency of yellowcedar mortality through time, which will be important for exploring mechanisms associated with tree death. In addition, identifying the range of time-since-death estimates of trees in different decay classes will be useful for estimating decay rates from one class to the next and determining dead wood persistence in different classes. Furthermore, information on the frequency and duration of partial cambial mortality allows for a better understanding of tree decline and the use of less-intensive sampling procedures in future studies.

\section{CONCLUSIONS}

Our pilot study provides a foundation for future studies to address new questions concerning growth-climate relations, patterns of mortality, and response of declining stands. We have identified unique growth patterns between our yellow-cedar chronologies from declining sites and those from similar sites in Alaska. Additional studies of growth-climate relations across multiple sites are underway to assess the extent to which yellow-cedar in British Columbia is vulnerable to damage from similar climatic stressors as those documented in Alaska and to determine spatial patterns of risk. Furthermore, we have demonstrated the feasibility of directly estimating time since death of standing dead yellow-cedar trees using dendrochronological techniques. Although limitations exist in the precision of time-sincedeath estimates, particularly as dead trees age and with regard to the presence of partial cambial mortality, sampling and analytical approaches can 
be designed to best account for these shortcomings when reconstructing population dynamics. Future studies that assess growth-climate relations and reconstruct the long-term population dynamics of yellow-cedar in declining stands will provide managers with information essential to project timber losses, changes to stands, and ecosystem reorganization in coastal forests.

\section{ACKNOWLEDGMENTS}

We thank Ron Diprose, Rachel Field, Harry Kope, Alex Marshall, Colin Nelson, and Mike Symons for assistance in the field, along with Kevin Johnstone, Jennifer Passmore, and Sonya Powell for assistance in the lab. Mike Grainger and the staff at the British Columbia Ministry of Forests and Range (BCMFR), North Coast Forest District, provided logistical support while in Prince Rupert. Colin Beier and Scott Sink kindly supplied their COFECHA outputs for use in Figure 5 and the Discussion section of the manuscript. We thank two anonymous reviewers for helpful comments. The BCMFR provided funding for this project.

\section{REFERENCES CITED}

Allen, C. D., A. K. Macalady, H. Chenchouni, D. Bachelet, N. McDowell, M. Vennetier, T. Kitzberger, A. Rigling, D. D. Breshears, E. H. Hogg, P. Gonzalez, R. Fensham, Z. Zhang, J. Castro, N. Demidova, J. Lim, G. Allard, S. W. Running, A. Semerci, and N. Cobb, 2010. A global overview of drought and heat-induced tree mortality reveals emerging climate change risks for forests. Forest Ecology and Management 259:660-684.

Amoroso, M. M., and L. D. Daniels, 2010. Cambial mortality in declining Austrocedrus chilensis forests: Implications for stand dynamics studies. Canadian Journal of Forest Research 40:885-893.

Barton, G. M., 1976. A review of yellow cedar (Chamaecyparis nootkatensis (D. Don) Spach) extractives and their importance to utilization. Wood and Fiber 8:172-176.

Beier, C. M., S. E. Sink, P. E. Hennon, D. V. D'Amore, and G. P. Juday, 2008. Twentieth-century warming and the dendroclimatology of declining yellow-cedar forests in southeastern Alaska. Canadian Journal of Forest Research 38:1319-1334.

Cook, E. R., 1985. A Time Series Analysis Approach to Tree-Ring Standardization. Ph.D. dissertation, University of Arizona, Tucson.

Cook, E. R., S. Shiyatov, and V. Mazepa, 1990. Estimation of the mean chronology. In Methods of Dendrochronology:
Applications in the Environmental Sciences, edited by E. R. Cook, and L. A. Kairiukstis, pp. 123-132. Kluwer Academic Publishers, Dordrecht.

D'Amore, D. V., and P. E. Hennon, 2006. Evaluation of soil saturation, soil chemistry, and early spring soil and air temperatures as risk factors in yellow-cedar decline. Global Change Biology 12:524-545.

D'Amore, D. V., P. E. Hennon, P. G. Schaberg, and G. J. Hawley, 2009. Adaptation to exploit nitrate in surface soils predisposes yellow-cedar to climate-induced decline while enhancing the survival of western redcedar: A new hypothesis. Forest Ecology and Management 258:2261-2268.

Daniels, L. D., J. Dobry, K. Klinka, and M. C. Feller, 1997. Determining year of death of logs and snags of Thuja plicata in southwestern coastal British Columbia. Canadian Journal of Forest Research 27:1132-1141.

Grissino-Mayer, H. D., 2001. Evaluating crossdating accuracy: a manual and tutorial for the computer program COFECHA. Tree-Ring Research 57:205-221.

Hennon, P. E., D. V. D'Amore, D. T. Wittwer, and J. P. Caouette, 2008. Yellow-cedar decline: Conserving a climatesensitive tree species as Alaska warms. In Integrated Restoration of Forested Ecosystems to Achieve Multiresource Benefits: Proceedings of the 2007 National Silviculture Workshop, edited by R. L. Deal, pp. 233-245. USDA Forest Service General Technical Report PNW-GTR-733.

Hennon, P. E., D. V. D'Amore, S. Zeglen, and M. Grainger, 2005. Yellow-Cedar Decline in the North Coast Forest District of British Columbia. USDA Forest Service Research Note PNW-RN-549.

Hennon, P. E., E. M. Hansen, and C. G. Shaw, III, 1990a. Dynamics of decline and mortality of Chamaecyparis nootkatensis in southeast Alaska. Canadian Journal of Botany 68:651-662.

Hennon, P. E., and C. G. Shaw, III, 1994. Did climatic warming trigger the onset and development of yellow-cedar decline in southeast Alaska? European Journal of Forest Pathology 24: 399-418.

Hennon, P. E., and C. G. Shaw, III, 1997. The enigma of yellow-cedar decline: What is killing these long-lived, defensive trees? Journal of Forestry 95:4-10.

Hennon, P. E., C. G. Shaw, III, and E. M. Hansen, 1990 b. Symptoms and fungal associations of declining Chamaecyparis nootkatensis in southeast Alaska. Plant Disease 74 : 267-273.

Hennon, P. E., C. G. Shaw, III, and E. M. Hansen, 1990c. Dating decline and mortality of Chamaecyparis nootkatensis in southeast Alaska. Forest Science 36:502-515.

Holmes, R. L., 1983. Computer-assisted quality control in tree-ring dating and measurement. Tree-Ring Bulletin 43: 69-78.

Kellner, A. M. E., C. P. Laroque, D. J. Smith, and A. S. Harestad, 2000. Chronological dating of high-elevation dead and dying trees on northern Vancouver Island, British Columbia. Northwest Science 74:242-247.

Lamb, M., and T. Wurtz (compilers), 2009. Forest Health Conditions in Alaska-2008. USDA Forest Service Forest Health Protection Report R10-PR-20. 
Laroque, C. P., and D. J. Smith, 1999. Tree-ring analysis of yellow-cedar (Chamaecyparis nootkatensis) on Vancouver Island, British Columbia. Canadian Journal of Forest Research 29:115-123.

Mast, J. N., and T. T. Veblen, 1994. A dendrochronological method of studying tree mortality patterns. Physical Geography 15:529-542.

Meidinger, D. V., and J. Pojar, Editors, 1991. Ecosystems of British Columbia. British Columbia Ministry of Forests Special Report Series 6.

Parish, R., 2005. Mount Cain, Alaska Yellow-Cedar Tree-Ring Record (CANA175). In International Tree-Ring Data Bank, edited by H. D. Grissino-Mayer, and H. C. Fritts, IGBP PAGES/World Data Center-A for Paleoclimatology. NOAA/ NGDC Paleoclimatology Program, Boulder.

Parish, R., and J. A. Antos, 2004. Structure and dynamics of an ancient montane forest in coastal British Columbia. Oecologia 141:562-576.

Parish, R., and J. A. Antos, 2006. Slow growth, long-lived trees, and minimal disturbance characterize the dynamics of an ancient, montane forest in coastal British Columbia. Canadian Journal of Forest Research 36:2826-2838.

$\mathrm{R}$ Development Core Team, 2007. R: A Language and Environment for Statistical Computing. R Foundation for Statistical Computing, Vienna.

Stokes, M. A., and T. L. Smiley, 1968. An Introduction to TreeRing Dating. University of Chicago Press, Chicago.

Wang, T., A. Hamann, D. L. Spittlehouse, and S. N. Aitken, 2006. Development of scale-free climate data for western Canada for use in resource management. International Journal of Climatology 26:383-397.

Westfall, J., and T. Ebata, 2009. 2008 Summary of Forest Health Conditions in British Columbia. British Columbia Ministry of Forests and Range Pest Management Report Number 15.

Yamaguchi, D. K., 1991. A simple method for cross-dating increment cores from living trees. Canadian Journal of Forest Research 21:414 416.

Received 5 June 2009; accepted 18 May 2010. 